\title{
América Latina y el Caribe alza su voz para reducir el impacto pandémico a través de las vacunas COVID-19
}

\author{
Latin America and the Caribbean raise their voices to reduce \\ pandemic impact through COVID-19 vaccines
}

Roberto Debbag*

* Vicepresidente de la Sociedad Latinoamericana de Infectología Pediátrica.

En enero de 2020 el mundo comenzó a hablar de un grave y potencial problema en la salud pública mundial. Fue la Organización Mundial de la Salud la que informó que el COVID-19 era una emergencia sanitaria, en marzo de ese mismo año declaró la pandemia y el primer caso se presentó en América Latina el 25 de febrero de 2020 (Brasil). A partir de los meses siguientes América Latina y el Caribe (ALC) han sido de las regiones del mundo más afectadas por el coronavirus tanto en número de casos como de muertes; si bien en nuestra región vive el $8.4 \%$ de la población mundial, un dato que muestra este impacto es que a finales de 2020 18.6\% de los contagiados y $27.8 \%$ de los fallecidos de todo el mundo vivían en ALC.

La pandemia ha aumentado la mortalidad en la región, al 31 de diciembre de 2020 se documentaron alrededor de 507,000 muertes debido a COVID-19, lo cual muy probablemente afectará los niveles de mortalidad regional y la esperanza de vida en nuestros países. Esto, sin duda, es reflejo de las desigualdades regionales, producto de los diversos estratos sociales que viven, sus condiciones étnicas, las situaciones migratorias, la corrupción política histórica con un gran impacto en las últimas décadas en los sistemas sanitarios, entre otros. Si esbozamos las desigualdades y la inequidad en el área de salud encontramos fundamentalmente

Citar como: Debbag R. América Latina y el Caribe alza su voz para reducir el impacto pandémico a través de las vacunas COVID-19. Rev Latin Infect Pediatr. 2021; 34 (2): 60-61. https://dx.doi.org/10.35366/100543

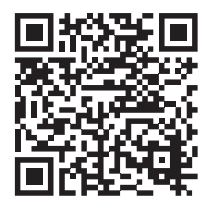

las dificultades de acceso a la atención médica, a una cobertura universal y a deficientes sistemas sanitarios de atención primaria que involucran todo nuestro ciclo de vida dentro de una región donde ocurre un paulatino aumento de la pobreza, situación que ha incrementado debido al impacto de las infecciones por coronavirus. En ALC el porcentaje de pobreza extrema ha aumentado de 7.8 a $11.3 \%$ de la población y la pobreza de 27.8 a más de $35 \%$ a finales de 2020.

También nuestra región se vio impactada por políticas sanitarias de confinamiento de la población en sus casas como forma de reducir el impacto, debido a las situaciones habitacionales y socioeconómicas, las cuales con sus prolongaciones en el tiempo y sin estrategias sanitarias de respuesta social, médica y epidemiológicas, generaron mayores efectos indeseables en la salud de las personas, en la salud regional y en la economía de las familias.

Las condiciones poblacionales debieron ser miradas con mayor detalle durante la pandemia en nuestra región, ejemplo de esto es que en ALC $81 \%$ de las poblaciones viven en localidades clasificadas como urbanas, de acuerdo con las definiciones nacionales, lo que la convierte en la región en desarrollo más urbanizada del mundo (Naciones Unidas, 2019) y $35 \%$ de la población vive en ciudades de más de un millón de habitantes, existiendo cinco grandes ciudades con 10 millones de habitantes o más (Buenos Aires, Ciudad de México, Lima, Río de Janeiro y Sao Paulo), por lo que esto fue un factor de riesgo en la transmisión de la infección en contextos de alta densidad demográfica, hacinamiento, la falta de acceso a servicios de agua y saneamiento, de electricidad y de 
Rev Latin Infect Pediatr. 2021; 34 (2): 60-61

Internet, y la precariedad y saturación del transporte público, observándose focos de contagios y mayor concentración de personas fallecidas.

Otras desigualdades ocurren en poblaciones indígenas y afrodescendientes, las cuales viven en escenarios de profundas desigualdades sociales, determinadas por el racismo estructural con altos índices de pobreza, acceso desigual a la educación, condiciones habitacionales deficitarias y un menor acceso a la salud. Los pueblos originarios se concentran en $80 \%$ en cinco países de ALC (Chile, Colombia, Guatemala, México y Perú) y un censo reciente que muestra las desigualdades indica que ocho millones de personas no tienen acceso a agua potable en sus viviendas y por lo tanto su acceso a sistemas sanitarios también es deficitario.

Además, no olvidemos que durante el año 2020 los responsables del manejo pandémico dieron lugar al cierre masivo de instituciones educativas como medida de control de transmisión viral y que 32 países cerraron sus escuelas, lo que afectó a más de 165 millones de niños, niñas y adolescentes. Esta interrupción aumentó las desigualdades en el aprendizaje relacionadas, fundamentalmente, en niños y niñas de nivel primaria y en los procesos de educación a distancia, en especial en los sectores más desaventajados que cuentan con menos recursos culturales y tecnológicos; aunque se diga que los hogares tienen acceso a Internet, ese acceso incrementado en los últimos años es, en la mayoría de los hogares, por conectividad móvil, con accesos prepagos, lo cual hace dificultosa su actividad digital educativa.

Todo lo mencionado con anterioridad impacta en la salud regional de nuestros niños y adultos y su mejoría dependerá de una serie de factores que reduzcan el tiempo de la pandemia y que fortalezcan los sistemas sanitarios en su acceso y en el control de la transmisión viral, que incluye como pilares fundamentales el rastreo, la detección de infectados, su asistencia sanitaria y sistemas en tiempo real de monitoreo genético de las variantes de COVID-19 en la región.

¿Cómo reducir entonces el tiempo pandémico? Una sola respuesta. El acceso a la vacunación COVID-19 en ALC depende a su vez de dos variables: la adquisición de vacunas y los programas de vacunación pandémicos. En relación a las adquisición de vacunas COVID-19 todos conocemos que actualmente en ALC no se tiene la cantidad de vacunas que se necesitan, ya que se han recibido alrededor de 40 millones de dosis que deberán ser repartidas entre 630 millones de personas, inicialmente y en forma prioritaria y rápida a más de 300 millones de adultos mayores de 70 años y pacientes con comorbilidades, con el fin de reducir la mortalidad relacionada con COVID-19. La cifra actual alcanza para administrar menos de seis dosis por cada 100 habitantes, manteniendo un criterio de dos por persona; hoy la región puede inmunizar alrededor de $3 \%$ de su población. Además, la cifra total de vacunas es engañosa con respecto a la disponibilidad en ALC para llegar a sus poblaciones (marzo 2021), ya que $87 \%$ de las dosis están sólo en cuatro países: Brasil (15 millones), Chile (8.6 millones), México y Argentina (cuatro millones). Coincide que los cuatro países integran el grupo de las cinco mayores economías de la región, mientras que otros países no han recibido dosis y otros cuentan con unas pocas miles, como Paraguay $(4,000)$, Ecuador $(73,000)$ o El Salvador $(20,000)$.

Asimismo, en ALC necesitamos que los programas de vacunación pandémicos sean robustos y eficaces. Estos programas, a mi entender, deben estar estructurados en cuatro pilares: 1. Evidencias médicas en relación con qué vacunas utilizar, a qué grupos prioritarios vacunar, etcétera; 2 . Implementación de Tecnologías de la Información y Comunicación (TICs), seguimiento de dosis y pacientes, registros de efectos indeseables, etcétera; 3 . Valores morales y de equidad que garanticen accesos, y 4. Plan de comunicación a través de médicos convencionales y nuevas vías de comunicación digital.

Por último, sólo me queda una reflexión: la única herramienta que disminuirá los efectos indeseables de esta pandemia y que proveerá salud a nuestra gente son las vacunas COVID-19. Pidamos con todas nuestras voces a los gobiernos y responsables sanitarios acceder a este bien tan preciado que son las vacunas COVID-19.

\footnotetext{
Correspondencia:

Roberto Debbag

E-mail: rdebbag@hotmail.com
} 